\title{
Prevalence and Factors Associated with Cumulative Anticholinergic Burden Among Older Long-Stay Nursing Home Residents with Overactive Bladder
}

\author{
Satabdi Chatterjee ${ }^{1} \cdot$ David Walker $^{2} \cdot$ Tomomi Kimura $^{3} \cdot$ Rajender R. Aparasu $^{1}$
}

Accepted: 7 January 2021 / Published online: 8 March 2021

(c) The Author(s) 2021

\begin{abstract}
Background Overactive bladder (OAB), the primary cause of urinary incontinence in nursing homes, is commonly treated with anticholinergic medications; however, the elderly population is vulnerable to the adverse effects associated with anticholinergic burden. Given the relatively high prevalence of $\mathrm{OAB}$ among nursing home residents, it is important to understand the magnitude of anticholinergic burden in this population.

Objectives The objectives of this study were to (1) examine the prevalence of cumulative anticholinergic burden among long-stay nursing home (LSNH) residents with OAB; and (2) identify the factors associated with varying levels of cumulative anticholinergic burden.

Methods This was a retrospective, cohort study using Minimum Data Set-linked Medicare claims data. Anticholinergic burden was determined based on the Anticholinergic Cognitive Burden scale and patient-specific dosing using defined daily dose. The Andersen Behavioral Model framework was used to identify the predisposing, enabling, and need factors associated with levels of anticholinergic burden. Multivariable logistic regression models were developed to determine the factors associated with levels of anticholinergic burden.

Results A total of 123,308 LSNH residents with OAB were identified; $87.2 \%$ had some degree of anticholinergic burden and $27.3 \%$ had high cumulative burden. Multiple factors were associated with higher levels of burden, including younger age, female sex, and non-Hispanic White ethnicity (predisposing factors); dual eligibility, Southern geographic region, and rural residence (enabling factors); and a number of comorbidities and concomitant medications (need factors).

Conclusions This study revealed a high level of anticholinergic burden among LSNH residents. Multiple factors were associated with a high level of burden. There is a need to optimize the use of anticholinergics due to their significant safety concerns in the LSNH setting.
\end{abstract}

\section{Key Points}

This study assesses the degree of anticholinergic burden present, as well as contributing factors, among nursing

Rajender R. Aparasu

raparasu@Central.UH.EDU

1 Department of Pharmaceutical Health Outcomes and Policy, College of Pharmacy, University of Houston, Houston, TX, USA

2 Medical Affairs, US, Astellas Pharma Global Development, Inc., Northbrook, IL, USA

3 Advanced Informatics and Analytics, Real World Data \& Evidence, Astellas US LLC, Northbrook, IL, USA home residents with overactive bladder.

The majority of residents had some degree of anticholinergic burden; a number of factors that were associated with having a high level of burden were identified.

Given the safety concerns associated with anticholinergic medications, ways by which anticholinergic burden can be mitigated among this particularly vulnerable population should be evaluated. 


\section{Introduction}

Overactive bladder $(\mathrm{OAB})$ is a constellation of urinary symptoms typically characterized by urgency, with or without urge urinary incontinence (UI), and accompanied by frequency and nocturia [1]. While the estimated prevalence of $\mathrm{OAB}$ in the US (between 16.5 and 23.3\%) indicates that it is a common condition among the general adult population, it is thought to be particularly burdensome within the nursing home setting $[2,3]$.

Despite the high burden associated with $\mathrm{OAB}$ in institutions, the prevalence within this setting and the characteristics of residents with $\mathrm{OAB}$ are only beginning to be understood. Recent analyses using Medicare claims data estimate that the prevalence of $\mathrm{OAB}$ among long-stay nursing home (LSNH) residents is $36 \%$, which is more than double that of some of the estimates for the general population [3, 4]. Furthermore, the comorbidity profiles of LSNH residents with OAB indicate that their underlying health status is potentially poor, and they are at an overall higher risk for all-cause mortality $[4,5]$.

Treatment patterns related to $\mathrm{OAB}$ within the nursing home setting are also not fully characterized, which is of particular concern given the overall health of these individuals as well as the potential for adverse events associated with polypharmacy [6]. Although comprehensive treatment guidelines exist, current literature indicates that the management of $\mathrm{OAB} / \mathrm{UI}$ in the nursing home setting is challenging $[7,8]$. Behavioral interventions are recommended as first-line treatment; however, multiple studies have found that nursing home staff do not have the adequate training or knowledge to manage $\mathrm{OAB} / \mathrm{UI}$ using these techniques [8-10]. Following behavioral therapies, the first line of pharmacotherapy in $\mathrm{OAB}$ patients typically consists of antimuscarinic agents, which are part of the group of oral anticholinergic medications [11]. Besides OAB, anticholinergic medications are indicated for a range of conditions, including respiratory, neurological/psychiatric, and gastrointestinal disorders [12]. Given that many of the conditions that are treated with anticholinergics increase in prevalence with age, it has been estimated that up to half of older adults have some degree of exposure to these drugs, including simultaneous use of multiple agents $[13,14]$. Cumulative exposure to anticholinergic medications ('anticholinergic burden') is directly related to an increased risk of central and peripheral adverse events (AEs) [15]. These are broad in nature and include dry mouth, constipation, falls and fractures, as well as neurological and behavioral issues such as delirium, cognitive impairment, and confusion [12, 14, 15]. Real-world data have shown that use of anticholinergic drugs among the elderly is associated with impairments in physical performance and the ability to perform activities of daily living (ADLs) [16]. Furthermore, recent studies have found that exposure to certain anticholinergic medications, including antimuscarinic agents used to treat $\mathrm{OAB}$, is associated with an increased risk of dementia [17-19]. Furthermore, the most recent version of the American Geriatrics Society Beers Criteria includes the recommendation for older adults, especially those with dementia, cognitive impairment or delirium, to avoid drugs with strong anticholinergic properties [20].

Previous studies that have examined anticholinergic burden among individuals with $\mathrm{OAB}$ are limited to the outpatient setting and are therefore representative of a less vulnerable population $[5,21,22]$; however, these studies have shown that outpatients with OAB had a greater degree of anticholinergic burden than those without OAB [5, 21, 22]. Although the magnitude of results varies between studies, Szabo et al. found that over $80 \%$ of individuals with OAB had some degree of anticholinergic burden [21]. Given the high prevalence of OAB among nursing home residents, their likely poorer health status relative to communitydwelling adults, and the risks associated with anticholinergic exposure, it is important to understand the magnitude as well as contributing factors of anticholinergic burden in this population. This will enable the future assessment of outcomes associated with anticholinergic burden within this population, and therefore inform targeted efforts to reduce burden, which may potentially result in reduced costs and improved patient outcomes. Therefore, the objectives of this study were to (1) examine the prevalence of cumulative anticholinergic burden among LSNH residents with OAB; and (2) determine the factors associated with varying levels of anticholinergic burden in these patients.

\section{Methods}

\subsection{Study Design and Data Source}

This was a retrospective, cohort study using Minimum Data Set (MDS)-linked Medicare claims data from January 2013 to December 2015, involving Parts A, B, and D [23]. The MDS is a standardized assessment tool and is performed on all residents in nursing homes who are eligible for Medicare or Medicaid funding. At a minimum, data on long-term residents are collected on a quarterly basis and includes information on patient functioning, cognition, mobility, behavioral symptoms, other non-behavioral symptoms, diagnoses, and medications [23]. Medicare claims data are available from the Centers for Medicare and Medicaid Services (CMS) upon request. Medicare Standard Analytical Files (SAFs) are restricted to claims submitted by fee-for-service enrollees and they do not include patients from Medicare managed care plans. SAFs include specific files on inpatients, outpatients, skilled nursing homes, carriers and durable 
medical equipment, as well as the MedPAR, Denominator, Vital Stats and Part D files [24, 25]. This study was approved under exempt category by the University of Houston Committee for the Protection of Human Subjects.

\subsection{Study Population}

As per the CMS definition, residents with at least one nursing home stay of at least 101 consecutive days were considered as LSNH patients and were included in the study [26]. Additionally, patients were required to be 65 years of age or older at the time of nursing home admission (index date), and to have medical/pharmaceutical coverage 6 months before, and a minimum of 12 months following the index date. Because Medicare Part D data were used to assess anticholinergic use, medications used during the first 100 days following admission (during which they are covered by Medicare Part A) were not captured in this study. Therefore, at least 280 days of nursing home stay following the index date were required in order to assess anticholinergic exposure over a 6-month follow-up period. Finally, patients were required to have at least one medication claim during the 6-month period starting on the 101st day of admission, in order to be included in the analytic sample. A schematic of patient enrollment and follow-up is depicted in Fig. 1; a flowchart depicting patient eligibility is presented in Fig. 2.

The presence of OAB was based on inpatient and/or outpatient International Classification of Diseases, Ninth/Tenth Revision (ICD-9/10) diagnosis codes or a claim for an OABspecific medication (darifenacin, fesoterodine, oxybutynin, solifenacin, tolterodine, trospium chloride, mirabegron, onabotulinumatoxin A) based on prescription fill records or Current Procedural Terminology (CPT) codes for onabotulinumatoxin A during their nursing home stay. Specific diagnostic and medication codes are outlined in electronic supplementary Tables 1 and 2, respectively.

\subsection{Anticholinergic Exposure}

Cumulative anticholinergic exposure was calculated using previously published methods that are designed to take into account a drug's anticholinergic activity along with patient-specific dosing $[17,27]$. In this study, anticholinergic medication use was assessed for each patient over a 6-month period starting from the 101st day of admission and was based on the medications listed in the Anticholinergic Cognitive Burden (ACB) scale [28]. The 4-point ACB scale is a validated, frequently utilized instrument that ranks the anticholinergic activity (range: 0 [none] -3 [severe]) of 104 drugs that are known to contribute at least some anticholinergic burden. A sum of the scores of each drug prescribed to a patient is therefore reflective of overall anticholinergic burden [21, 28].

A multistep process was subsequently used to obtain patient-specific dosing. Following the assessment of anticholinergic medication dispensing, the World Health Organization's (WHO's) defined daily dose (DDD) was used to standardize the differences in dosing across medications. Defined as "the assumed average maintenance dose per day for a drug used for its main indication in adults", the DDD is currently the recommended international standard for drug utilization monitoring and research [29]. A list of drugs according to Anatomical Therapeutic Classification (ATC) codes and the corresponding values for each DDD are available from the WHO Collaborating Centre for Drug Statistics Methodology [29]. In order to adjust for the daily exposure associated with each anticholinergic dispensing, the product of the number of daily units and the unit dose

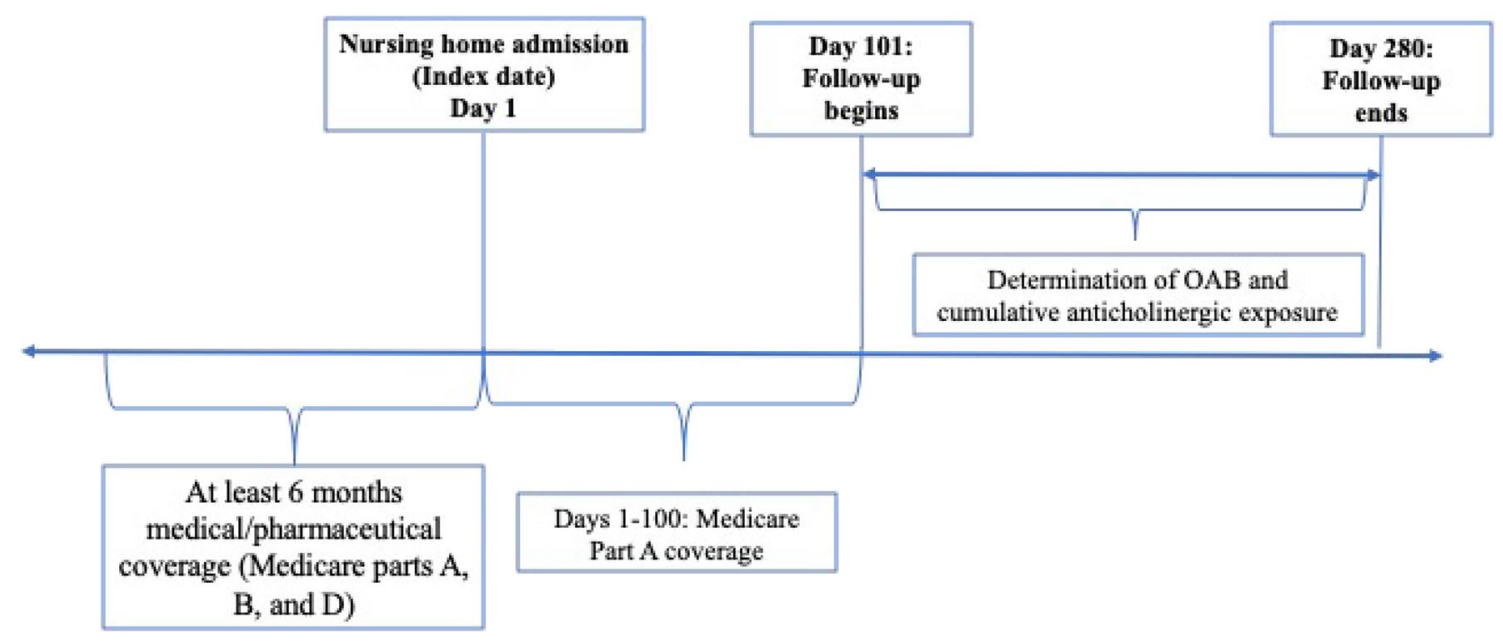

Fig. 1 Patient enrollment and follow-up. $O A B$ overactive bladder 
Fig. 2 Cohort derivation. $L S N H$ long-stay nursing home, $M D S$ Minimum Data Set, $O A B$ overactive bladder

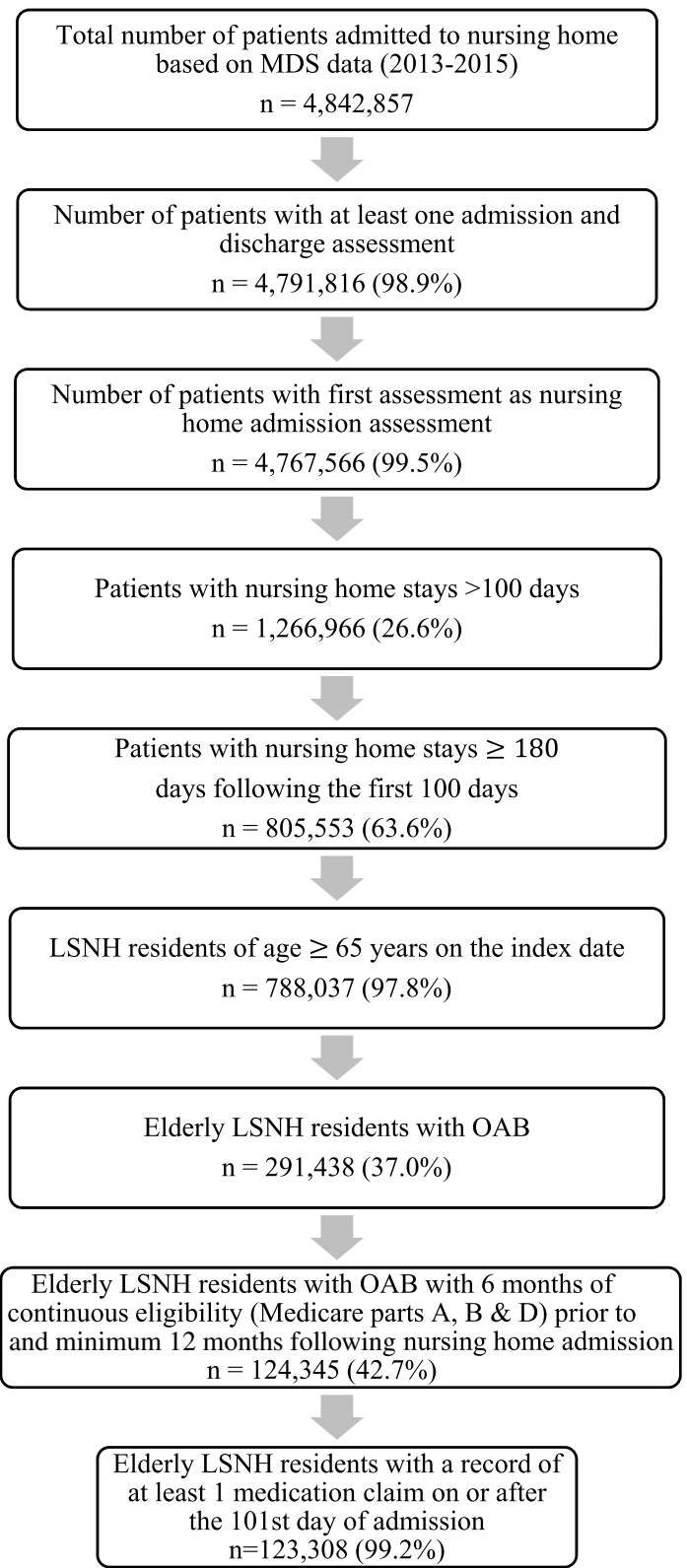

Abbreviations: LSNH = long-stay nursing home; MDS = Minimum Data Set; $\mathrm{OAB}=$ overactive bladder was subsequently divided by the DDD to obtain the standardized daily dose (SDD) [27].

Based on the anticholinergic medication dispensing and patient-specific dosing, each SDD for each patient was multiplied by the corresponding ACB scale score to obtain the drug-specific Standardized Daily Anticholinergic Exposure (SDACE). For each day of the study period, values for the SDACE were totaled, resulting in a summated Standard Daily Anticholinergic Exposure (SumSDACE). Cumulative exposure was obtained for each patient by summing the daily SumSDACE values over the 6-month follow-up period starting from the 101st day after admission [27]. Finally, patients were then assigned into groups based on cumulative exposure. Previously published cut-off values of cumulative SumSDACE scores were used to classify patients with no (0), low (1-89), moderate (90-499) or high $(\geq 500)$ anticholinergic burden [21].

\subsection{Factors Associated with Anticholinergic Burden}

In recognition of the multiple individual and external factors that are related to a patient's anticholinergic exposure, the Andersen Behavioral Model (ABM) was used to identify available variables that were potentially associated 
Table 1 Baseline predisposing, enabling, and need factors from the Andersen Behavioral Model (ABM)

\section{Predisposing factors}

Age

Marital status

\section{Enabling factors}

Medicare/medicaid dual eligibility

Need factors

Baseline comorbidities

Falls

Multiple sclerosis

Elixhauser comorbidities

Hypertension

Cardiac arrhythmias

Chronic pulmonary disease

Renal failure

Weight loss

Obesity

Rheumatoid arthritis

Peptic ulcer

Metastatic cancer

Baseline medication use

Antidepressants

Calcium channel blockers

Antipsychotics

Other medication use

Benzodiazepine derivatives

Other antihistamines- for systemic use

Other

Body mass index

Urinary toileting program

Bowel continence

Depressed mood indicator
Gender

Region

Fracture

Spinal cord injury

Fluid and electrolyte disorders

Peripheral vascular disorders

Other neurological disorders

Hypothyroidism

Valvular disease

Coagulopathy

Liver disease

Drug abuse

Lymphoma

Diuretics

Anticonvulsants

Antiparkinson agents

Glucocorticoids

Antihistamines-aminoalkyl ethers

Baseline ACB score

Urinary continence

Response to toileting program

MDS cognitive performance scale

\section{Race/ethnicity}

Urban/rural

Parkinson's disease

Neurogenic bladder

Depression

Congestive heart failure

Diabetes

Psychoses

Deficiency anemias

Paralysis

Blood loss anemias

Alcohol abuse

AIDS/HIV

Beta-blockers

ACE inhibitors

Alpha-blockers

Natural opium alkaloids

Antihistamines-phenothiazine derivatives

Bladder continence management

Current toileting program or trial

Activities of Daily Living

$A C B$ anticholinergic cognitive burden, $A C E$ angiotensin-converting enzyme, $A I D S / H I V$ acquired immunodeficiency syndrome/human immunodeficiency virus; $M D S$ Minimum Data Set

with the observed levels of anticholinergic burden [30]. The ABM was developed in 1968 by Robert Andersen as a framework to identify predictors of health care utilization and has been extensively used to study different aspects of health care utilization. Andersen posited that both individual and contextual determinants drive health care utilization, and that these determinants are comprised of predisposing, enabling, and need factors. Examples of factors at the individual level that are predisposing to health care use include patient demographics, whereas contextual factors include the demographic and social composition of communities. Similarly, individual enabling factors include patient income and insurance status, while contextual enablers include proximity to health care providers. Finally, individual need factors include subjective factors, such as perceived general health, as well as objective factors, including current healthcare utilization. At the contextual level, need can be assessed by epidemiological indicators of population health $[30,31]$. Notably, the ABM has recently been used in several multinational studies to assess factors associated with long-term care use [32-35].

For this study, factors were selected based on those used in similar studies and were contingent on availability in the Medicare and MDS databases. Selected predisposing, enabling, and need factors were assessed during the baseline period (within the 6 months before nursing home admission). Predisposing factors included age, sex, race/ethnicity, and marital status; enabling factors include dual eligibility, geographical region, urban-rural residence; and need factors included baseline medications and comorbidities. 
Table 2 Selected baseline characteristics of elderly NH residents with OAB, categorized by levels of cumulative anticholinergic burden Elderly long-stay NH patients with OAB having prescription records during 101-280 days of follow-up $(N=123,308)^{\mathrm{a}}$

\begin{tabular}{|c|c|c|c|c|}
\hline \multirow[t]{2}{*}{ Characteristics } & $\begin{array}{l}\text { No burden } \\
\text { (Score } 0)\end{array}$ & $\begin{array}{l}\text { Low burden } \\
\text { (Score } 1-89 \text { ) }\end{array}$ & $\begin{array}{l}\text { Moderate burden } \\
\text { (Score 90-499) }\end{array}$ & $\begin{array}{l}\text { High burden } \\
\text { (Score } 500 \text { or more) }\end{array}$ \\
\hline & $N=15,801(12.8 \%)$ & $N=22,215(18.0 \%)$ & $N=51,668(41.9 \%)$ & $N=33,624(27.3 \%)$ \\
\hline \multicolumn{5}{|l|}{ Predisposing factors } \\
\hline \multicolumn{5}{|l|}{ Age categories } \\
\hline $65-74$ years $(n=24,067)$ & $\begin{array}{l}2341(14.8 \%) \\
(9.7 \%)\end{array}$ & $\begin{array}{l}3309(14.9 \%) \\
(13.7 \%)\end{array}$ & $\begin{array}{l}9687(18.8 \%) \\
(40.0 \%)\end{array}$ & $\begin{array}{l}8730(26.0 \%) \\
(36.0 \%)\end{array}$ \\
\hline $75-84$ years $(n=43,269)$ & $\begin{array}{l}5271(33.4 \%) \\
(12.2 \%)\end{array}$ & $\begin{array}{l}7578(34.1 \%) \\
(17.5 \%)\end{array}$ & $\begin{array}{l}18,250(35.3 \%) \\
(42.2 \%)\end{array}$ & $\begin{array}{l}12,170(36.2 \%) \\
(28.0 \%)\end{array}$ \\
\hline $85+$ years $(n=55,964)$ & $\begin{array}{l}8181(51.8 \%) \\
(14.6 \%)\end{array}$ & $\begin{array}{l}11,328(51.0 \%) \\
(20.2 \%)\end{array}$ & $\begin{array}{l}23,731(46.0 \%) \\
(42.4 \%)\end{array}$ & $\begin{array}{l}12,724(37.9 \%) \\
(22.7 \%)\end{array}$ \\
\hline \multicolumn{5}{|l|}{ Gender } \\
\hline Male $(n=33,511)$ & $\begin{array}{l}4891(30.1 \%) \\
(14.6 \%)\end{array}$ & $\begin{array}{l}6721(30.3 \%) \\
(20.1 \%)\end{array}$ & $\begin{array}{l}13,933(27.0 \%) \\
(41.6 \%)\end{array}$ & $\begin{array}{l}7966(23.7 \%) \\
(23.8 \%)\end{array}$ \\
\hline Female $(n=89,437)$ & $\begin{array}{l}10,910(69.1 \%) \\
(12.2 \%)\end{array}$ & $\begin{array}{l}15,494(69.8 \%) \\
(17.3 \%)\end{array}$ & $\begin{array}{l}37,735(73.1 \%) \\
(41.8 \%)\end{array}$ & $\begin{array}{l}25,658(76.3 \%) \\
(28.7 \%)\end{array}$ \\
\hline \multicolumn{5}{|l|}{ Race/ethnicity ${ }^{\mathrm{b}}$} \\
\hline $\begin{array}{l}\text { Non-Hispanic White }(n= \\
107,659)\end{array}$ & $\begin{array}{l}13,183(83.6 \%) \\
(12.2 \%)\end{array}$ & $\begin{array}{l}19,063(86.0 \%) \\
(17.7 \%)\end{array}$ & $\begin{array}{l}45,222(87.7 \%) \\
(42 \%)\end{array}$ & $\begin{array}{l}30,191(89.9 \%) \\
(28.0 \%)\end{array}$ \\
\hline $\begin{array}{l}\text { Non-Hispanic Black ( } n= \\
10,785)\end{array}$ & $\begin{array}{l}1690(10.7 \%) \\
(15.7 \%)\end{array}$ & $\begin{array}{l}2103(9.5 \%) \\
(19.5 \%)\end{array}$ & $\begin{array}{l}4493(8.7 \%) \\
(41.7 \%)\end{array}$ & $\begin{array}{l}2499(7.4 \%) \\
(23.2 \%)\end{array}$ \\
\hline Hispanics $(n=1802)$ & $\begin{array}{l}303(1.9 \%) \\
(16.8 \%)\end{array}$ & $\begin{array}{l}370(1.7 \%) \\
(20.5 \%)\end{array}$ & $\begin{array}{l}777(1.5 \%) \\
(43.1 \%)\end{array}$ & $\begin{array}{l}352(1.1 \%) \\
(19.5 \%)\end{array}$ \\
\hline Other $(n=2847)$ & $\begin{array}{l}598(3.8 \%) \\
(21 \%)\end{array}$ & $\begin{array}{l}639(2.9 \%) \\
(22.4 \%)\end{array}$ & $\begin{array}{l}1085(2.1 \%) \\
(38.1 \%)\end{array}$ & $\begin{array}{l}525(1.6 \%) \\
(18.4 \%)\end{array}$ \\
\hline \multicolumn{5}{|l|}{ Marital status $^{\mathrm{a}}$} \\
\hline Married $(n=29,429)$ & $\begin{array}{l}4014(25.6 \%) \\
(13.6 \%)\end{array}$ & $\begin{array}{l}5762(26.1 \%) \\
(19.6 \%)\end{array}$ & $\begin{array}{l}12,351(24.1 \%) \\
(42.0 \%)\end{array}$ & $\begin{array}{l}7302(21.8 \%) \\
(24.8 \%)\end{array}$ \\
\hline Unmarried $(n=93,138)$ & $\begin{array}{l}11,672(74.1 \%) \\
(12.5 \%)\end{array}$ & $\begin{array}{l}16,309(73.9 \%) \\
(17.5 \%)\end{array}$ & $\begin{array}{l}39,032(76.0 \%) \\
(41.9 \%)\end{array}$ & $\begin{array}{l}26,125(78.2 \%) \\
(28.0 \%)\end{array}$ \\
\hline \multicolumn{5}{|l|}{ Enabling factors } \\
\hline $\begin{array}{l}\text { Medicare/Medicaid dual } \\
\text { eligible }(n=56,966)\end{array}$ & $\begin{array}{l}6620(41.9 \%) \\
(11.6 \%)\end{array}$ & $\begin{array}{l}9336(42.0 \%) \\
(16.4 \%)\end{array}$ & $\begin{array}{l}23,928(46.3 \%) \\
(42.0 \%)\end{array}$ & $\begin{array}{l}17,082(50.8 \%) \\
(30.0 \%)\end{array}$ \\
\hline \multicolumn{5}{|l|}{ Region $^{\mathrm{b}}$} \\
\hline South $(n=44,987)$ & $\begin{array}{l}5290(33.5 \%) \\
(11.8 \%)\end{array}$ & $\begin{array}{l}7864(35.4 \%) \\
(17.5 \%)\end{array}$ & $\begin{array}{l}19,225(37.2 \%) \\
(42.7 \%)\end{array}$ & $\begin{array}{l}12,608(37.5 \%) \\
(28.0 \%)\end{array}$ \\
\hline Northeast $(n=26,586)$ & $\begin{array}{l}3529(22.3 \%) \\
(13.3 \%)\end{array}$ & $\begin{array}{l}5387(24.3 \%) \\
(20.3 \%)\end{array}$ & $\begin{array}{l}11,114(21.5 \%) \\
(41.8 \%)\end{array}$ & $\begin{array}{l}6556(19.5 \%) \\
(24.7 \%)\end{array}$ \\
\hline Midwest $(n=39,969)$ & $\begin{array}{l}4918(31.1 \%) \\
(12.3 \%)\end{array}$ & $\begin{array}{l}6699(30.2 \%) \\
(16.8 \%)\end{array}$ & $\begin{array}{l}16,745(32.4 \%) \\
(41.9 \%)\end{array}$ & $\begin{array}{l}11,607(34.5 \%) \\
(29.0 \%)\end{array}$ \\
\hline West $(n=11,750)$ & $\begin{array}{l}2062(13.1 \%) \\
(17.5 \%)\end{array}$ & $\begin{array}{l}2264(10.2 \%) \\
(19.3 \%)\end{array}$ & $\begin{array}{l}4577(8.9 \%) \\
(39.0 \%)\end{array}$ & $\begin{array}{l}2847(8.5 \%) \\
(24.2 \%)\end{array}$ \\
\hline Others $(n=10)$ & $\begin{array}{l}1(0.0 \%) \\
(10.0 \%)\end{array}$ & $\begin{array}{l}1(0.0 \%) \\
(10.0 \%)\end{array}$ & $\begin{array}{l}5(0.0 \%) \\
(50.0 \%)\end{array}$ & $\begin{array}{l}3(0.0 \%) \\
(30.0 \%)\end{array}$ \\
\hline \multicolumn{5}{|l|}{ Urban-rural } \\
\hline Rural $(n=35,152)$ & $\begin{array}{l}4102(26.0 \%) \\
(11.7 \%)\end{array}$ & $\begin{array}{l}5549(26.0 \%) \\
(15.8 \%)\end{array}$ & $\begin{array}{l}14,770(28.6 \%) \\
(42.0 \%)\end{array}$ & $\begin{array}{l}10,731(32.0 \%) \\
(30.5 \%)\end{array}$ \\
\hline Urban $(n=88,156)$ & $\begin{array}{l}11,699(74.0 \%) \\
(13.3 \%)\end{array}$ & $\begin{array}{l}16,666(75.0 \%) \\
(18.9 \%)\end{array}$ & $\begin{array}{l}36,898(71.4 \%) \\
(41.9 \%)\end{array}$ & $\begin{array}{l}22,893(68.1 \%) \\
(26.0 \%)\end{array}$ \\
\hline \multicolumn{5}{|l|}{ Baseline need factors } \\
\hline Falls & $8362(55.9 \%)$ & $12,609(56.8 \%)$ & $28,485(55.1 \%)$ & $18,554(55.2 \%)$ \\
\hline Fracture & $2783(17.6 \%)$ & $4090(18.4 \%)$ & $8823(17.1 \%)$ & $5220(15.5 \%)$ \\
\hline
\end{tabular}


Table 2 (continued)

\begin{tabular}{|c|c|c|c|c|}
\hline \multirow[t]{2}{*}{ Characteristics } & $\begin{array}{l}\text { No burden } \\
\text { (Score } 0)\end{array}$ & $\begin{array}{l}\text { Low burden } \\
\text { (Score 1-89) }\end{array}$ & $\begin{array}{l}\text { Moderate burden } \\
\text { (Score 90-499) }\end{array}$ & $\begin{array}{l}\text { High burden } \\
\text { (Score } 500 \text { or more) }\end{array}$ \\
\hline & $N=15,801(12.8 \%)$ & $N=22,215(18.0 \%)$ & $N=51,668(41.9 \%)$ & $N=33,624(27.3 \%)$ \\
\hline Parkinson's disease & $3(0.0 \%)$ & $3(0.0 \%)$ & $8(0.0 \%)$ & $3(0.0 \%)$ \\
\hline Multiple sclerosis & $117(0.7 \%)$ & $138(0.6 \%)$ & $459(0.9 \%)$ & $369(1.1 \%)$ \\
\hline Spinal cord injury & $10(0.1 \%)$ & $9(0.0 \%)$ & $23(0.0 \%)$ & $12(0.0 \%)$ \\
\hline Neurogenic bladder & $186(1.2 \%)$ & $233(1.1 \%)$ & $642(1.2 \%)$ & $553(1.6 \%)$ \\
\hline
\end{tabular}

$A C B$ anticholinergic burden, $L S N H$ long-stay nursing home, $M D S$ Minimum Data Set, $O A B$ overactive bladder

${ }^{\mathrm{a}}$ Based on MDS Admission Assessment and includes missing data. Denominator for \% calculation is those who have non-missing data; ${ }^{\mathrm{b}} \mathrm{Based}$ on enrollment files and includes missing data. Denominator for $\%$ calculation is those who have non-missing data; italicized values indicate the $\%$ based on the row total, non-italicized percent values refer to the percentage of patients in each anticholinergic burden category

Comorbidities included, but were not limited to, Elixhauser comorbidities (such as heart failure, cardiac arrhythmias, hypertension, diabetes, depression, psychoses, obesity) [36], and neurological, cardiovascular, and psychiatric conditions. Medications included angiotensin-converting enzyme (ACE) inhibitors, antidepressants, $\beta$-blockers, calcium channel blockers, and diuretics, among others. Additional need factors included level of urinary and bowel continence, ability to perform ADLs, and cognitive performance captured in the MDS. The predisposing, enabling, and need factors considered for this study are listed in Table 1.

\subsection{Statistical Analyses}

The prevalence and distribution of anticholinergic burden (no, low, moderate, or high) among LSNH residents with OAB were summarized using descriptive statistics (mean, standard deviations, and proportions). The frequency of the predictive factors across the four levels of anticholinergic burden were summarized and the differences were evaluated via analysis of variance (ANOVA) for continuous variables and Chi-squares for categorical variables.

Two multivariable logistic regression models were developed in order to determine the factors that were predictive of level of anticholinergic burden. First, level of anticholinergic burden was dichotomized into moderate/high (SumSDACE score $\geq 90$ ) versus low/no (SumSDACE score 0-89), the latter of which served as the reference group. The predictors of anticholinergic burden were assessed using a logistic regression model adjusted for the factors identified through the ABM. Similarly, predictors of moderate burden (90-499) and high burden $(\geq 500)$ versus low burden (1-89) were assessed using a multinomial logistic regression model, also adjusting for factors identified through the ABM. For both models, odds ratios (ORs) with $95 \%$ confidence intervals (CIs) were estimated.

\section{Results}

\subsection{Patient Characteristics}

A total of $124,345 \mathrm{LSNH}$ residents with OAB were identified in the MDS (Fig. 2). The mean age was $82.6( \pm 8.28)$ years, $72.7 \%$ were female, and $87.3 \%$ were non-Hispanic White.

A total of 123,308 (99.2\%) of these residents had at least one medication claim during the 6-month period starting from the 101st day of admission and formed the analytical sample (Table 2; electronic supplementary Table 3). Most of these patients $(87.2 \%)$ had some anticholinergic burden during the 6-month period starting from the 101st day of admission; $12.8 \%$ had none, $18.0 \%$ had low, $41.9 \%$ had moderate, and $27.3 \%$ had high cumulative anticholinergic burden. The LSNH residents with a higher level of anticholinergic burden tended to be younger (65-74 years of age; $26.0 \%$ ), while those with no $(51.8 \%)$ or low (51.0\%) anticholinergic burden were older ( $\geq 85$ years of age). Among the $85+$ years age group, $14.6 \%$ had no anticholinergic burden, versus $12.2 \%$ of those aged $75-84$ years and $9.7 \%$ of those aged $65-74$ years. Conversely, $22.7 \%$ of those age $85+$ years had high levels of anticholinergic burden, versus $28.0 \%$ of those aged $75-84$ and $36.0 \%$ of those aged $65-74$ years.

Individuals with high anticholinergic burden had a higher baseline comorbidity burden overall, as well as higher rates of concomitant medication use, compared with those with no burden. Regarding cognition, residents with moderate and high levels of anticholinergic burden accounted for the majority of individuals in all categories (intact, mild, moderate, moderately severe, and severe impairment). However, the proportion of residents with high levels of anticholinergic burden decreased as the level of cognitive impairment increased. For example, $11.8 \%$ of residents with intact cognition had no anticholinergic burden, while $28.8 \%$ had high levels of burden. Conversely, among residents with severe cognitive impairment, $17.7 \%$ had no anticholinergic burden, 
while $19.9 \%$ had high levels of anticholinergic burden. Similarly, the proportion of residents with moderate or high levels of anticholinergic burden decreased as level of UI increased. Specifically, $28 \%$ of residents who were 'always continent' had no or low levels of anticholinergic burden, while $71.9 \%$ had moderate or high levels of burden. Among residents who were 'always incontinent', 35.9\% had no or low levels of anticholinergic burden, while $64.1 \%$ had moderate or high levels of burden. Finally, of the 4489 (4.8\%) residents who were indicated as having a depressed mood, $65.5 \%$ had moderate or high levels of anticholinergic burden, versus $68.9 \%$ of residents who were not indicated as having a depressed mood.

\subsection{Moderate/High Versus Low/No Anticholinergic Burden}

Results from the logistic regression are presented in Table 3. Several variables within the categories of predisposing, enabling, and need factors demonstrated an association with having moderate/high anticholinergic burden versus low/ no burden. Among predisposing factors, age was negatively associated with moderate/high burden: Individuals 75-84 years of age had a $25 \%$ lower likelihood of moderate/high anticholinergic burden compared with individuals 65-74 years of age (OR 0.75, 95\% CI 0.72-0.78). Females were $25 \%$ more likely to have moderate/high anticholinergic burden compared with males (OR 1.25, 95\% CI 1.21-1.29). Non-Hispanic Blacks, Hispanics, and other racial groups were less likely to have moderate/high burden compared with non-Hispanic Whites.

Of the enabling factors, the likelihood of having moderate/high burden was higher among those with dual eligibility (OR 1.16, 95\% CI 1.13-1.20). LSNH residents located in the Northeast (OR 0.89, 95\% CI 0.86-0.93) and West (OR 0.82, 95\% CI 0.78-0.86) regions had a lower likelihood of having moderate/high burden compared with those residing in the South. Furthermore, the odds of having moderate/high burden was also lower among LSNH residents in urban versus rural areas (OR 0.83, 95\% CI 0.81-0.86).

Multiple need factors were associated with the level of anticholinergic burden. Comorbidities that were associated with having a moderate/high level of burden include history of multiple sclerosis, neurogenic bladder, Elixhauser comorbidities (such as heart failure, cardiac arrhythmias, hypertension, diabetes, depression, psychoses, obesity), higher body mass index (BMI) levels, occasional/frequent UI, and depressed mood indicators. Conversely, cognitive impairment and bowel incontinence were associated with reduced odds of having moderate/high burden. Finally, all categories of concomitant medication use observed at baseline were associated with a statistically significant increase in the odds of having moderate/high burden.

\subsection{Moderate and High Burden Versus Low Anticholinergic Burden}

Results from the multinomial regression model are presented in Table 4. Overall, findings were consistent with those observed with the model above. Among the predisposing factors, female sex was positively associated with higher anticholinergic burden (moderate vs. low burden: OR 1.16, 95\% CI 1.11-1.21; high vs. low burden: OR 1.40, 95\% CI 1.33-1.46), whereas older age was negatively associated with higher burden levels. The age association was most pronounced when high burden was compared with low burden (OR 0.47, 95\% CI 0.44-0.49) for the 85 years and older age group. Finally, non-Hispanic Blacks, Hispanics, and other racial groups were less likely to have high anticholinergic burden compared with non-Hispanic Whites.

Of the enabling factors, there was again an increased likelihood of higher anticholinergic burden associated with dual eligibility (moderate vs. low burden: OR 1.11, 95\% CI 1.08-1.15; and high vs. low burden: OR 1.22, 95\% CI 1.17-1.26). Residence in the Northeast and West (vs. South) regions as well as residence in urban (vs. rural) areas were associated with a decreased likelihood of having moderate and high burden levels.

Finally, multiple need factors were associated with anticholinergic burden. Specifically, history of multiple sclerosis, several Elixhauser comorbidities, baseline concomitant medications, and higher BMI levels were positively associated with the likelihood of moderate and high burden versus low burden, while neurogenic bladder and occasional/ frequent UI were positively associated with the likelihood of high burden only. Furthermore, severe cognitive impairment was associated with a decreased likelihood of higher levels of anticholinergic burden (moderate versus low burden [OR $0.76,95 \%$ CI $0.71-0.81]$ and high versus low burden [OR $0.65,95 \%$ CI $0.60-0.70])$.

Overall, a dose-response-like relationship was observed with respect to the magnitude of association for high versus low burden compared with moderate versus low burden for all predisposing and enabling factors and the above need factors.

\section{Discussion}

To the authors' knowledge, the present study is among the first efforts to characterize the degree of anticholinergic burden among LSNH residents with OAB in the US. Results suggest that nearly $90 \%$ of LSNH residents with OAB were exposed to varying levels of anticholinergic burden, with two-thirds demonstrating moderate-to-high anticholinergic burden. Previous studies using US administrative claims data to assess anticholinergic use and outcomes among a 
Table 3 Logistic regression model for predictors of moderate/high anticholinergic burden (cumulative score $\geq 90$ ) versus no/low burden (cumulative score $<90$ )

\begin{tabular}{|c|c|c|c|}
\hline Characteristics & OR & $95 \% \mathrm{CI}$ & $p$ value \\
\hline \multicolumn{4}{|l|}{ Predisposing factors } \\
\hline \multicolumn{4}{|l|}{ Age categories, years } \\
\hline $65-74$ & Reference & & \\
\hline $75-84$ & 0.75 & $0.72-0.78$ & $<0.0001$ \\
\hline $85+$ & 0.64 & $0.61-0.67$ & $<0.0001$ \\
\hline \multicolumn{4}{|l|}{ Sex } \\
\hline Male & Reference & & \\
\hline Female & 1.25 & $1.21-1.29$ & $<0.0001$ \\
\hline \multicolumn{4}{|l|}{ Race/ethnicity } \\
\hline Non-Hispanic White & Reference & & \\
\hline Non-Hispanic Black & 0.74 & $0.70-0.77$ & $<0.0001$ \\
\hline Hispanics & 0.81 & $0.73-0.90$ & 0.0001 \\
\hline Other & 0.75 & $0.69-0.81$ & $<0.0001$ \\
\hline \multicolumn{4}{|l|}{ Marital status } \\
\hline Unmarried & Reference & & \\
\hline Married & 0.94 & $0.91-0.97$ & 0.0001 \\
\hline Missing & 0.91 & $0.77-1.07$ & 0.24 \\
\hline \multicolumn{4}{|l|}{ Enabling characteristics } \\
\hline Medicare/Medicaid dual eligible & 1.16 & $1.13-1.20$ & $<0.0001$ \\
\hline \multicolumn{4}{|l|}{ Region } \\
\hline South & Reference & & \\
\hline Northeast & 0.89 & $0.86-0.93$ & $<0.0001$ \\
\hline Midwest & 0.99 & $0.96-1.03$ & 0.61 \\
\hline West & 0.82 & $0.78-0.86$ & $<0.0001$ \\
\hline \multicolumn{4}{|l|}{ Urban-rural } \\
\hline Rural & Reference & & \\
\hline Urban & 0.83 & $0.81-0.86$ & $<0.0001$ \\
\hline \multicolumn{4}{|l|}{ Need characteristics } \\
\hline Falls/fractures & 0.96 & $0.93-0.99$ & 0.0024 \\
\hline Parkinson's disease & 0.82 & $0.27-2.53$ & 0.73 \\
\hline Multiple sclerosis & 1.59 & $1.36-1.86$ & $<0.0001$ \\
\hline Spinal cord injury & 0.98 & $0.53-1.80$ & 0.95 \\
\hline Neurogenic bladder & 1.21 & $1.07-1.37$ & 0.0030 \\
\hline \multicolumn{4}{|l|}{ Elixhauser comorbidities } \\
\hline Congestive heart failure & 1.41 & $1.37-1.46$ & $<0.0001$ \\
\hline Cardiac arrhythmias & 1.15 & $1.11-1.18$ & $<0.0001$ \\
\hline Valvular disease & 1.04 & $1.01-1.08$ & 0.0084 \\
\hline Pulmonary circulation disorders & 1.10 & $1.05-1.14$ & $<0.0001$ \\
\hline Peripheral vascular disorders & 1.03 & $0.99-1.06$ & 0.07 \\
\hline Hypertension & 1.11 & $1.04-1.19$ & 0.003 \\
\hline Paralysis & 0.95 & $0.91-0.99$ & 0.01 \\
\hline Other neurological disorders & 0.90 & $0.87-0.92$ & $<0.0001$ \\
\hline Chronic pulmonary disease & 1.14 & $1.10-1.17$ & $<0.0001$ \\
\hline Diabetes & 1.09 & $1.06-1.12$ & $<0.0001$ \\
\hline Hypothyroidism & 1.03 & $1.00-1.06$ & 0.04 \\
\hline Renal failure & 1.02 & $0.99-1.05$ & 0.16 \\
\hline Liver disease & 0.98 & $0.94-1.02$ & 0.33 \\
\hline Peptic ulcer & 1.01 & $0.96-1.08$ & 0.69 \\
\hline Lymphoma & 0.93 & $0.84-1.03$ & 0.14 \\
\hline
\end{tabular}


Table 3 (continued)

\begin{tabular}{|c|c|c|c|}
\hline Characteristics & OR & $95 \% \mathrm{CI}$ & $p$ value \\
\hline Metastatic cancer & 0.95 & $0.88-1.02$ & 0.17 \\
\hline Solid tumor without metastasis & 1.02 & $0.98-1.05$ & 0.40 \\
\hline Rheumatoid arthritis & 1.12 & $1.08-1.17$ & $<0.0001$ \\
\hline Coagulopathy & 0.97 & $0.94-1.01$ & 0.15 \\
\hline Obesity & 1.24 & $1.20-1.29$ & $<0.0001$ \\
\hline Weight loss & 0.87 & $0.84-0.89$ & $<0.0001$ \\
\hline Fluid and electrolyte disorders & 0.95 & $0.92-0.98$ & 0.003 \\
\hline Blood loss anemias & 0.98 & $0.93-1.03$ & 0.39 \\
\hline Deficiency anemias & 0.95 & $0.93-0.98$ & 0.0014 \\
\hline Alcohol abuse & 0.97 & $0.91-1.04$ & 0.44 \\
\hline Drug abuse & 1.22 & $1.15-1.30$ & $<0.0001$ \\
\hline Psychoses & 1.10 & $1.07-1.13$ & $<0.0001$ \\
\hline Depression & 1.14 & $1.10-1.17$ & $<0.0001$ \\
\hline \multicolumn{4}{|l|}{ Medication use } \\
\hline$\alpha$-Blockers & 1.08 & $1.01-1.16$ & 0.03 \\
\hline$\beta$-Blockers & 1.75 & $1.71-1.81$ & $<0.0001$ \\
\hline Calcium channel blockers & 1.06 & $1.03-1.09$ & 0.0002 \\
\hline ACE inhibitors & 0.90 & $0.88-0.93$ & $<0.0001$ \\
\hline Diuretics & 1.95 & $1.89-2.01$ & $<0.0001$ \\
\hline Antidepressants & 1.18 & $1.14-1.23$ & $<0.0001$ \\
\hline Antipsychotics & 1.40 & $1.35-1.44$ & $<0.0001$ \\
\hline Anticonvulsants & 1.18 & $1.14-1.21$ & $<0.0001$ \\
\hline Antiparkinson agents & 1.23 & $1.18-1.28$ & $<0.0001$ \\
\hline Exposure to ACB level 2 or 3 medications & 1.44 & $1.39-1.50$ & $<0.0001$ \\
\hline \multicolumn{4}{|l|}{ Body mass index } \\
\hline Underweight & Reference & & \\
\hline Normal weight & 0.91 & $0.86-0.97$ & 0.002 \\
\hline Overweight & 1.14 & $1.10-1.18$ & $<0.0001$ \\
\hline Obese & 1.30 & $1.25-1.36$ & $<0.0001$ \\
\hline Missing & 0.93 & $0.84-1.02$ & 0.13 \\
\hline \multicolumn{4}{|l|}{ Urinary continence } \\
\hline Always continent & Reference & & \\
\hline Occasionally incontinent & 1.12 & $1.06-1.19$ & $<0.0001$ \\
\hline Frequently incontinent & 1.08 & $1.02-1.15$ & 0.006 \\
\hline Always incontinent & 1.04 & $0.97-1.12$ & 0.25 \\
\hline Not rated & 1.18 & $1.08-1.28$ & 0.0001 \\
\hline Missing & 1.02 & $0.58-1.80$ & 0.95 \\
\hline \multicolumn{4}{|l|}{ Bowel continence } \\
\hline Always continent & Reference & & \\
\hline Occasionally incontinent & 0.90 & $0.85-0.95$ & $<0.0001$ \\
\hline Frequently incontinent & 0.85 & $0.81-0.89$ & $<0.0001$ \\
\hline Always incontinent & 0.79 & $0.74-0.84$ & $<0.0001$ \\
\hline Not rated & 0.96 & $0.85-1.08$ & 0.46 \\
\hline Missing & 1.13 & $0.64-2.00$ & 0.66 \\
\hline \multicolumn{4}{|l|}{ MDS Cognitive Performance Scale } \\
\hline Intact & Reference & & \\
\hline Mild & 1.02 & $0.90-1.16$ & 0.72 \\
\hline Moderate & 0.84 & $0.78-0.90$ & $<0.0001$ \\
\hline Moderately severe & 0.80 & $0.73-0.88$ & $<0.0001$ \\
\hline Severe & 0.69 & $0.66-0.73$ & $<0.0001$ \\
\hline
\end{tabular}


Table 3 (continued)

\begin{tabular}{llll}
\hline Characteristics & OR & $95 \%$ CI & $p$ value \\
\hline Missing & 0.83 & $0.78-0.89$ & \\
Activities of daily living & & & \\
Independent & Reference & 0.0001 \\
Limited/extensive assistance & 0.98 & $0.90-1.06$ & 0.57 \\
Dependent & 0.98 & $0.93-1.02$ & 0.29 \\
Missing & 0.76 & $0.66-0.88$ & \\
Depressed mood indicator & & & \\
No & Reference & & \\
Yes & 1.10 & $1.03-1.18$ & 0.002 \\
Missing & 1.17 & $1.09-1.26$ & $<0.0001$ \\
\hline
\end{tabular}

$A C B$ anticholinergic burden, $A C E$ angiotensin-converting enzyme, $C I$ confidence interval, $O R$ odds ratio

general adult population have indicated that over $80 \%$ of individuals with $\mathrm{OAB}$ exhibited at least some degree of anticholinergic burden [21]. While efforts are scarce, studies from other countries have also revealed that anticholinergic burden is present among their respective $\mathrm{OAB}$ populations. For example, OAB patients identified in one study, using pharmacy claims data in Japan, had markedly higher exposure to anticholinergic medications than individuals without $\mathrm{OAB}$ [22]. When assessed using the ACB scale, the number of OAB patients who had exposure to at least one anticholinergic medication was $45.7 \%$ versus $9.3 \%$ of individuals without OAB. Furthermore, exposure among OAB patients was largely driven by the use of antimuscarinic agents. In another study using real-world data from Germany, analyses revealed that $47.5 \%$ of OAB patients had exposure to anticholinergic drugs, as indicated by an ACB score of $>0$. Almost 25\% had a score of $\geq 3$, which is considered to be clinically relevant [37]. It is important to note that the results of the present study cannot be directly compared with those from other efforts, given differences in study populations and settings as well as variations in quantifying anticholinergic exposure. However, the degree of anticholinergic exposure observed among LSNH residents appears to be consistent with reports of overall higher levels among individuals with $\mathrm{OAB}$, if not greater in magnitude.

The high levels of anticholinergic burden observed in this study, coupled with the overall vulnerability of LSNH residents, highlights a substantial opportunity to reduce and prevent AEs associated with exposure to anticholinergic medications. While the specific impact of reducing exposure to anticholinergic medications has not been explored among LSNH residents, other studies evaluating interventions designed to mitigate the effects of polypharmacy have revealed significant benefits to this population. For example, in the study by Kojima et al., an intervention that resulted in a reduction from 16.6 to 15.5 average medications per resident was associated with a monthly savings of $\$ 30.71$ per resident. Anticholinergic medications were among the classes of medications evaluated, and, although not described in extensive detail, reductions in use were associated with reductions in monthly costs [38]. Thus, it is likely that efforts targeted specifically towards reducing exposure to anticholinergic drugs would result in appreciable benefits, including a decrease in AEs and associated cost savings, and improvements in quality of life.

In this study, a number of factors were found to be associated with anticholinergic burden. Interestingly, age exhibited a negative association, a finding that is in contrast to other studies that have shown higher levels of burden among older versus younger individuals [21,37]. When taken in tandem with the observation that exposure was also reduced among individuals with impaired cognition, the observed relationship between age and exposure suggests that there may be increased awareness among physicians regarding the updated Beers' Criteria and the risks of anticholinergic use in these groups. This can be further implied given that older studies of residents in nursing homes found high levels of anticholinergic exposure among patients with dementia [39], whereas newer studies have reported that patients with dementia have lower levels of exposure [40]. However, in contrast, LSNH residents with multiple comorbidities had a higher exposure to anticholinergic medications. When considered alongside similar observations from other studies [37], it appears that the underlying health status of those with high exposure is poorer than those with less exposure. Indeed, studies have shown an association between exposure to anticholinergic medications and a number of peripheral and central AEs [41, 42]. Conversely, with regard to OAB medications, clinical trials have shown no negative impact of certain antimuscarinics on certain outcomes, including those related to cognition and mental health [43-45]. However, the design of the present study only permits associations between the factors and anticholinergic burden among LSNH residents with OAB; whether or not the relationships 
Table 4 Multinomial logistic regression for predictors of moderate (cumulative score: 90-499) and high anticholinergic burden (cumulative score: $>500$ ) compared with low burden (cumulative score: 1-89)

\begin{tabular}{|c|c|c|c|c|c|c|}
\hline Characteristics & $\begin{array}{l}\text { Moderate- to low- } \\
\text { burden OR }\end{array}$ & $95 \% \mathrm{CI}$ & $p$ value & $\begin{array}{l}\text { High- to low- } \\
\text { burden OR }\end{array}$ & $95 \% \mathrm{CI}$ & $p$ value \\
\hline \multicolumn{7}{|l|}{ Predisposing factors } \\
\hline \multicolumn{7}{|l|}{ Age categories, years } \\
\hline $65-74$ & Reference & & & & & \\
\hline $75-84$ & 0.82 & $0.78-0.86$ & $<0.0001$ & 0.62 & $0.59-0.66$ & $<0.0001$ \\
\hline $85+$ years & 0.74 & $0.70-0.78$ & $<0.0001$ & 0.47 & $0.44-0.49$ & $<0.0001$ \\
\hline \multicolumn{7}{|l|}{ Sex } \\
\hline Male & Reference & & & & & \\
\hline Female & 1.16 & $1.11-1.21$ & $<0.0001$ & 1.40 & $1.33-1.46$ & $<0.0001$ \\
\hline \multicolumn{7}{|l|}{ Race/ethnicity } \\
\hline Non-Hispanic White & Reference & & & & & \\
\hline Non-Hispanic Black & 0.85 & $0.80-0.90$ & $<0.0001$ & 0.71 & $0.66-0.76$ & $<0.0001$ \\
\hline Hispanics & 0.95 & $0.84-1.09$ & 0.46 & 0.70 & $0.60-0.81$ & $<0.0001$ \\
\hline Other & 0.85 & $0.77-0.94$ & 0.002 & 0.68 & $0.60-0.76$ & $<0.0001$ \\
\hline \multicolumn{7}{|l|}{ Marital status } \\
\hline Unmarried & Reference & & & & & \\
\hline Married & 0.96 & $0.92-1.00$ & 0.03 & 0.87 & $0.84-0.91$ & $<0.0001$ \\
\hline Missing & 0.89 & $0.73-1.10$ & 0.27 & 0.96 & $0.76-1.20$ & 0.69 \\
\hline \multicolumn{7}{|l|}{ Enabling characteristics } \\
\hline Medicare/Medicaid dual eligible & 1.11 & $1.08-1.15$ & $<0.0001$ & 1.22 & $1.17-1.26$ & $<0.0001$ \\
\hline \multicolumn{7}{|l|}{ Region } \\
\hline South & Reference & & & & & \\
\hline Northeast & 0.90 & $0.86-0.94$ & $<0.0001$ & 0.86 & $0.82-0.91$ & $<0.0001$ \\
\hline Midwest & 0.99 & $0.95-1.04$ & 0.84 & 1.06 & $1.01-1.10$ & 0.02 \\
\hline West & 0.89 & $0.84-0.94$ & 0.0001 & 0.88 & $0.82-0.94$ & 0.0002 \\
\hline \multicolumn{7}{|l|}{ Urban-rural } \\
\hline Rural & Reference & & & & & \\
\hline Urban & 0.87 & $0.84-0.91$ & $<0.0001$ & 0.76 & $0.73-0.79$ & $<0.0001$ \\
\hline \multicolumn{7}{|l|}{ Need characteristics } \\
\hline Falls/fractures & 0.95 & $0.92-0.98$ & 0.0024 & 0.93 & $0.89-0.96$ & $<0.0001$ \\
\hline Parkinson's disease & 1.37 & $0.35-5.55$ & 0.65 & 0.48 & $0.07-3.19$ & 0.44 \\
\hline Multiple sclerosis & 1.43 & $1.17-1.74$ & 0.0005 & 1.55 & $1.26-1.91$ & $<0.0001$ \\
\hline Spinal cord injury & 1.18 & $0.54-2.61$ & 0.68 & 1.01 & $0.41-2.52$ & 0.97 \\
\hline Neurogenic bladder & 1.14 & $0.97-1.33$ & 0.12 & 1.41 & $1.19-1.66$ & $<0.0001$ \\
\hline \multicolumn{7}{|l|}{ Elixhauser comorbidities } \\
\hline Congestive heart failure & 1.26 & $1.21-1.31$ & $<0.0001$ & 1.55 & $1.49-1.62$ & $<0.0001$ \\
\hline Cardiac arrhythmias & 1.04 & $1.003-1.08$ & 0.03 & 1.29 & $1.23-1.34$ & $<0.0001$ \\
\hline Valvular disease & 1.03 & $0.99-1.07$ & 0.09 & 1.03 & $0.99-1.07$ & 0.15 \\
\hline Pulmonary circulation disorders & 1.06 & $1.007-1.11$ & 0.03 & 1.08 & $1.03-1.14$ & 0.003 \\
\hline Peripheral vascular disorders & 1.01 & $0.98-1.05$ & 0.51 & 1.003 & $0.96-1.05$ & 0.90 \\
\hline Hypertension & 1.007 & $0.92-1.10$ & 0.87 & 0.87 & $0.78-0.97$ & 0.01 \\
\hline Paralysis & 0.96 & $0.91-1.01$ & 0.13 & 0.94 & $0.89-0.99$ & 0.03 \\
\hline Other neurological disorders & 0.93 & $0.89-0.96$ & $<0.0001$ & 0.86 & $0.83-0.89$ & $<0.0001$ \\
\hline Chronic pulmonary disease & 1.08 & $1.04-1.12$ & $<0.0001$ & 1.14 & $1.10-1.19$ & $<0.0001$ \\
\hline Diabetes & 1.07 & $1.04-1.11$ & $<0.0001$ & 1.16 & $1.12-1.21$ & $<0.0001$ \\
\hline Hypothyroidism & 1.02 & $0.98-1.05$ & 0.34 & 1.05 & $1.01-1.09$ & 0.010 \\
\hline Renal failure & 1.03 & $0.99-1.07$ & 0.06 & 0.99 & $0.95-1.02$ & 0.45 \\
\hline Liver disease & 0.96 & $0.91-1.01$ & 0.13 & 0.99 & $0.94-1.01$ & 0.90 \\
\hline Peptic ulcer & 0.99 & $0.93-1.07$ & 0.96 & 0.98 & $0.91-1.06$ & 0.59 \\
\hline
\end{tabular}


Table 4 (continued)

\begin{tabular}{|c|c|c|c|c|c|c|}
\hline Characteristics & $\begin{array}{l}\text { Moderate- to low- } \\
\text { burden OR }\end{array}$ & $95 \% \mathrm{CI}$ & $p$ value & $\begin{array}{l}\text { High- to low- } \\
\text { burden OR }\end{array}$ & $95 \% \mathrm{CI}$ & $p$ value \\
\hline Lymphoma & 0.94 & $0.84-1.03$ & 0.29 & 0.92 & $0.80-1.05$ & 0.20 \\
\hline Metastatic cancer & 0.97 & $0.89-1.06$ & 0.53 & 0.91 & $0.82-1.06$ & 0.06 \\
\hline Solid tumor without metastasis & 1.01 & $0.97-1.06$ & 0.66 & 1.02 & $0.97-1.07$ & 0.44 \\
\hline Rheumatoid arthritis & 1.04 & $0.99-1.09$ & 0.09 & 1.15 & $1.09-1.21$ & $<0.0001$ \\
\hline Coagulopathy & 0.96 & $0.91-0.99$ & 0.04 & 0.97 & $0.92-1.01$ & 0.16 \\
\hline Obesity & 1.17 & $1.12-1.23$ & $<0.0001$ & 1.26 & $1.19-1.32$ & $<0.0001$ \\
\hline Weight loss & 0.90 & $0.87-0.93$ & $<0.0001$ & 0.82 & $0.79-0.86$ & $<0.0001$ \\
\hline Fluid and electrolyte disorders & 0.97 & $0.94-1.01$ & 0.17 & 0.92 & $0.88-0.96$ & 0.0001 \\
\hline Blood loss anemias & 0.99 & $0.93-1.04$ & 0.62 & 0.92 & $0.87-0.98$ & 0.01 \\
\hline Deficiency anemias & 0.95 & $0.92-0.99$ & 0.01 & 0.94 & $0.90-0.97$ & 0.0007 \\
\hline Alcohol abuse & 0.96 & $0.89-1.04$ & 0.28 & 0.90 & $0.82-0.98$ & 0.01 \\
\hline Drug abuse & 1.08 & $1.003-1.17$ & 0.04 & 1.26 & $1.17-1.37$ & $<0.0001$ \\
\hline Psychoses & 1.04 & $1.001-1.07$ & 0.04 & 1.03 & $0.99-1.07$ & 0.19 \\
\hline Depression & 1.08 & $1.04-1.13$ & 0.0001 & 1.17 & $1.12-1.23$ & $<0.0001$ \\
\hline \multicolumn{7}{|l|}{ Medication use } \\
\hline$\alpha$-Blockers & 1.08 & $0.99-1.18$ & 0.09 & 1.08 & $0.98-1.19$ & 0.12 \\
\hline$\beta$-Blockers & 1.24 & $1.19-1.28$ & $<0.0001$ & 1.32 & $1.27-1.37$ & $<0.0001$ \\
\hline Calcium channel blockers & 1.06 & $1.02-1.09$ & 0.002 & 1.14 & $1.01-1.18$ & $<0.0001$ \\
\hline ACE inhibitors & 0.96 & $0.93-0.99$ & 0.03 & 0.89 & $0.86-0.93$ & $<0.0001$ \\
\hline Diuretics & 1.63 & $1.57-1.69$ & $<0.0001$ & 1.82 & $1.75-1.90$ & $<0.0001$ \\
\hline Antidepressants & 1.07 & $1.03-1.12$ & 0.002 & 1.26 & $1.20-1.32$ & $<0.0001$ \\
\hline Antipsychotics & 1.01 & $0.98-1.05$ & 0.50 & 1.11 & $1.07-1.15$ & $<0.0001$ \\
\hline Anticonvulsants & 1.12 & $1.08-1.16$ & $<0.0001$ & 1.23 & $1.18-1.28$ & $<0.0001$ \\
\hline Antiparkinson agents & 1.14 & $1.09-1.20$ & $<0.0001$ & 1.44 & $1.37-1.52$ & $<0.0001$ \\
\hline Exposure to ACB level 2 or 3 medications & 1.28 & $1.22-1.34$ & $<0.0001$ & 1.52 & $1.45-1.60$ & $<0.0001$ \\
\hline \multicolumn{7}{|l|}{ Body mass index } \\
\hline Underweight & Reference & & & & & \\
\hline Normal weight & 0.92 & $0.86-0.99$ & 0.03 & 0.99 & $0.91-1.08$ & 0.80 \\
\hline Overweight & 1.17 & $1.11-1.22$ & 0.0001 & 1.09 & $1.04-1.15$ & 0.0007 \\
\hline Obese & 1.28 & $1.21-1.35$ & $<0.0001$ & 1.31 & $1.23-1.39$ & $<0.0001$ \\
\hline Missing & 0.91 & $0.80-1.02$ & 0.11 & 0.94 & $0.81-1.08$ & 0.38 \\
\hline \multicolumn{7}{|l|}{ Urinary continence } \\
\hline Always continent & Reference & & & & & \\
\hline Occasionally incontinent & 1.07 & $0.99-1.15$ & 0.05 & 1.15 & $1.07-1.24$ & 0.0002 \\
\hline Frequently incontinent & 1.06 & $0.99-1.13$ & 0.12 & 1.12 & $1.03-1.20$ & 0.005 \\
\hline Always incontinent & 1.03 & $0.94-1.12$ & 0.51 & 1.08 & $0.98-1.18$ & 0.13 \\
\hline Not rated & 1.07 & $0.97-1.18$ & 0.19 & 1.35 & $1.21-1.50$ & $<0.0001$ \\
\hline Missing & 0.83 & $0.41-1.70$ & 0.63 & 0.85 & $0.39-1.82$ & 0.67 \\
\hline \multicolumn{7}{|l|}{ Bowel continence } \\
\hline Always continent & Reference & & & & & \\
\hline Occasionally incontinent & 0.95 & $0.89-1.008$ & 0.09 & 0.87 & $0.81-0.93$ & 0.0001 \\
\hline Frequently incontinent & 0.90 & $0.85-0.96$ & 0.003 & 0.74 & $0.69-0.79$ & $<0.0001$ \\
\hline Always incontinent & 0.89 & $0.83-0.96$ & $<0.0001$ & 0.69 & $0.64-0.75$ & $<0.0001$ \\
\hline Not rated & 1.02 & $0.88-1.18$ & 0.79 & 0.94 & $0.80-1.10$ & 0.42 \\
\hline Missing & 1.49 & $0.73-3.04$ & 0.27 & 1.28 & $0.60-2.76$ & 0.53 \\
\hline \multicolumn{7}{|l|}{ MDS Cognitive Performance Scale } \\
\hline Intact & Reference & & & & & \\
\hline Mild & 1.15 & $0.98-1.35$ & 0.09 & 1.02 & $0.85-1.21$ & 0.85 \\
\hline Moderate & 0.83 & $0.76-0.91$ & $<0.0001$ & 0.82 & $0.75-0.91$ & $<0.0001$ \\
\hline
\end{tabular}


Table 4 (continued)

\begin{tabular}{|c|c|c|c|c|c|c|}
\hline Characteristics & $\begin{array}{l}\text { Moderate- to low- } \\
\text { burden OR }\end{array}$ & $95 \% \mathrm{CI}$ & $p$ value & $\begin{array}{l}\text { High- to low- } \\
\text { burden OR }\end{array}$ & $95 \% \mathrm{CI}$ & $p$ value \\
\hline Moderately severe & 0.81 & $0.72-0.91$ & 0.0003 & 0.75 & $0.65-0.85$ & $<0.0001$ \\
\hline Severe & 0.76 & $0.71-0.81$ & $<0.0001$ & 0.65 & $0.60-0.70$ & $<0.0001$ \\
\hline Missing & 0.88 & $0.82-0.95$ & 0.0008 & 0.79 & $0.72-0.86$ & $<0.0001$ \\
\hline \multicolumn{7}{|l|}{ Activities of daily living } \\
\hline Independent & Reference & & & & & \\
\hline Limited/extensive assistance & 0.94 & $0.85-1.04$ & 0.25 & 0.94 & $0.84-1.05$ & 0.26 \\
\hline Dependent & 0.97 & $0.92-1.04$ & 0.49 & 0.92 & $0.87-0.99$ & 0.01 \\
\hline Missing & 0.80 & $0.67-0.95$ & 0.01 & 0.75 & $0.62-0.90$ & 0.003 \\
\hline \multicolumn{7}{|l|}{ Depressed mood indicator } \\
\hline No & Reference & & & & & \\
\hline Yes & 1.06 & $0.97-1.16$ & 0.18 & 1.08 & $0.98-1.19$ & 0.14 \\
\hline Missing & 1.08 & $0.99-1.19$ & 0.09 & 1.19 & $1.08-1.31$ & 0.0005 \\
\hline
\end{tabular}

$A C B$ anticholinergic burden, $A C E$ angiotensin-converting enzyme, $C I$ confidence interval, $O R$ odds ratio

observed are casual in nature cannot be determined. Therefore, future research is needed in order determine whether the relationships observed in the present study are causal in nature. Additionally, while the level of anticholinergic burden according to type of OAB medication (antimuscarinics and/or mirabegron) received is reported here (electronic supplementary Table 3), further examination of this relationship is beyond the scope of the present study. Thus, future research should examine anticholinergic exposure and outcomes according to type of OAB treatment.

The limitations of this study include those that are inherent to any endeavor using administrative claims data. These include issues primarily related to the use of medication claims and diagnostic codes to ascertain study outcomes as well as the generalizability of study findings. Regarding the former, while a prescription claim indicates the dispensation of a given medication, whether or not it was actually taken or administered cannot be verified. This could potentially result in the overestimation of anticholinergic burden. Furthermore, while diagnostic codes are a standard means to identify diagnoses in health services research, their accuracy is potentially affected by patient and clinician communication, misinterpretation of diagnostic tests, changes in diagnostic criteria, and errors in coding assignment [46]. Finally, while the database used in this study provides a fairly robust range of variables for analyses, there are likely many unmeasurable variables that impact anticholinergic burden.

Regarding study generalizability, findings are representative of Medicare fee-for-service LSNH enrollees and therefore may not be applicable to those covered by Medicare managed care plans. Furthermore, because the inclusion criteria required Medicare Parts A, B, and D coverage in the 6 months before and a minimum of 12 months after nursing home admission, this could limit the generalizability of the findings. Furthermore, patients who were in the nursing home for an extended length of time prior to 2013 may have been excluded from the study as a result of the inclusion criteria. Additionally, patients who died within the first 6 months after admission would also have been excluded, which could potentially bias the study sample towards those who were less sick. In both cases, it is unknown to what extent these patients may have differed from those who were included in the study sample.

\section{Conclusion}

The study found that nearly $90 \%$ of LSNH residents with $\mathrm{OAB}$ were exposed to varying levels of anticholinergic burden, with two-thirds demonstrating moderate-to-high anticholinergic burden. Several predisposing, enabling, and need factors were associated with moderate and high anticholinergic burden in LSNH residents with OAB. While there is an increased focus on anticholinergic medications given the safety concerns, there still exists a large degree of anticholinergic burden among older individuals in long-term care settings. The degree of anticholinergic burden present among LSNH residents with OAB indicates that the need to optimize the use of these medications continues. Future studies should attempt to determine to what degree anticholinergic burden can be lessened by the use of non-anticholinergic medications where possible, as well as any anticipated benefits in terms of health care resource use and associated costs and patient quality of life. More work is needed for targeted efforts that may reduce unnecessary anticholinergic burden and thereby improve the overall health of the LSNH population. 
Supplementary Information The online version contains supplementary material available at https://doi.org/10.1007/s40266-021-00833-X.

\section{Declarations}

Funding This study was funded by Astellas Pharma. Medical writing/ editorial support was provided by Meagan Harwood from Broadstreet HEOR and funded by the study sponsor.

Conflict of interest David Walker and Tomomi Kimura are employees of Astellas and may own Astellas stock. Rajender Aparasu reports grants from Incyte and Novartis, outside the submitted work. Satabdi Chatterjee has no conflicts of interest to declare.

Ethics approval This study was approved under exempt category by the University of Houston Committee for the Protection of Human Subjects.

Consent to participate Not applicable.

Consent for publication Not applicable.

Availability of data and material data Data are not available due to the CMS data use restrictions for research identifiable files.

Code availability Not applicable.

Author contributions All authors contributed to the study conception and design, writing of the manuscript, and read and approved the final manuscript. Data analysis was performed by Satabdi Chatterjee and Rajender Aparasu.

Open Access This article is licensed under a Creative Commons Attribution-NonCommercial 4.0 International License, which permits any non-commercial use, sharing, adaptation, distribution and reproduction in any medium or format, as long as you give appropriate credit to the original author(s) and the source, provide a link to the Creative Commons licence, and indicate if changes were made. The images or other third party material in this article are included in the article's Creative Commons licence, unless indicated otherwise in a credit line to the material. If material is not included in the article's Creative Commons licence and your intended use is not permitted by statutory regulation or exceeds the permitted use, you will need to obtain permission directly from the copyright holder. To view a copy of this licence, visit http://creativecommons.org/licenses/by-nc/4.0/.

\section{References}

1. Abrams P, Andersson K-E, Apostolidis A, Birder L, Bliss D, Brubaker $\mathrm{L}$, et al. 6th international consultation on incontinence. Recommendations of the international scientific committee: evaluation and treatment of urinary incontinence, pelvic organ prolapse and faecal incontinence. Neurourol Urodyn. 2018;37(7):2271-2. https://doi.org/10.1002/nau.23551.

2. Resnick NM, Yalla SV, Laurino E. The pathophysiology of urinary incontinence among institutionalized elderly persons. N Engl J Med. 1989;320(1):1-7. https://doi.org/10.1056/nejm198901 053200101.

3. Reynolds WS, Fowke J, Dmochowski R. The burden of overactive bladder on US public health. Curr Bladder Dysfunct Rep. 2016;11(1):8-13. https://doi.org/10.1007/s11884-016-0344-9.
4. Sura SD, Aparasu RR. PUK19 overactive bladder patients in the nursing homes: resident characteristics and treatment pattern. Value Health. 2019;22:S384. https://doi.org/10.1016/j. jval.2019.04.1873.

5. Suehs BT, Caplan EO, Hayden J, Ng DB, Gaddy RR. The relationship between anticholinergic exposure and falls, fractures, and mortality in patients with overactive bladder. Drugs Aging. 2019;36(10):957-67. https://doi.org/10.1007/s40266-019-00694 -5 .

6. Mortazavi SS, Shati M, Keshtkar A, Malakouti SK, Bazargan M, Assari S. Defining polypharmacy in the elderly: a systematic review protocol. BMJ Open. 2016;6(3):e010989. https://doi. org/10.1136/bmjopen-2015-010989.

7. Fantl JA, Newman D, Colling J. Urinary incontinence in adults: acute and chronic management: 1996 update. AHCPR Clinical Practice Guidelines, No. 2. Rockville: Agency for Health Care Policy and Research (AHCPR); 1996.

8. McDaniel C, Ratnani I, Fatima S, Abid MH, Surani S. Urinary incontinence in older adults takes collaborative nursing efforts to improve. Cureus. 2020;12(7):e9161. https://doi.org/10.7759/cureu s.9161.

9. Collette C, Bravo G, le Tu M. Development of a urinary incontinence educational program using a competency-based approach and case method. J Nurses Staff Dev. 2009;25(4):E5-10. https:// doi.org/10.1097/NND.0b013e3181ae140d.

10. Rahman AN, Schnelle JF, Yamashita T, Patry G, Prasauskas R. Distance learning: a strategy for improving incontinence care in nursing homes. Gerontologist. 2010;50(1):121-32. https://doi. org/10.1093/geront/gnp126.

11. Apostolidis A. Antimuscarinics in the treatment of OAB: is there a first-line and a second-line choice? Curr Drug Targets. 2015;16(11):1187-97. https://doi.org/10.2174/138945011666615 0518102021.

12. Ruxton K, Woodman RJ, Mangoni AA. Drugs with anticholinergic effects and cognitive impairment, falls and all-cause mortality in older adults: a systematic review and meta-analysis. $\mathrm{Br}$ J Clin Pharmacol. 2015;80(2):209-20. https://doi.org/10.1111/ bcp. 12617.

13. Gorup E, Rifel J, Petek ŠM. Anticholinergic burden and most common anticholinergic-acting medicines in older general practice patients. Zdr Varst. 2018;57(3):140-7. https://doi. org/10.2478/sjph-2018-0018.

14. Araklitis G, Cardozo L. Safety issues associated with using medication to treat overactive bladder. Expert Opin Drug Saf. 2017;16(11):1273-80. https://doi.org/10.1080/14740 338.2017.1376646.

15. Salahudeen MS, Duffull SB, Nishtala PS. Anticholinergic burden quantified by anticholinergic risk scales and adverse outcomes in older people: a systematic review. BMC Geriatr. 2015;15:31. https ://doi.org/10.1186/s12877-015-0029-9.

16. Landi F, Russo A, Liperoti R, Cesari M, Barillaro C, Pahor M, et al. Anticholinergic drugs and physical function among frail elderly population. Clin Pharmacol Ther. 2007;81(2):235-41. https://doi.org/10.1038/sj.clpt.6100035.

17. Gray SL, Anderson ML, Dublin S, Hanlon JT, Hubbard R, Walker R, et al. Cumulative use of strong anticholinergics and incident dementia: a prospective cohort study. JAMA Intern Med. 2015;175(3):401-7. https://doi.org/10.1001/jamaintern med.2014.7663.

18. Fox C, Richardson K, Maidment ID, Savva GM, Matthews FE, Smithard D, et al. Anticholinergic medication use and cognitive impairment in the older population: the medical research council cognitive function and ageing study. J Am Geriatr Soc. 2011;59(8):1477-83. https://doi.org/10.111 $1 /$ j.1532-5415.2011.03491.x. 
19. Welk B, McArthur E. Increased risk of dementia among patients with overactive bladder treated with an anticholinergic medication compared to a beta-3 agonist: a population-based cohort study. BJU Int. 2020;126(1):183-90. https://doi.org/10.1111/bju.15040.

20. American Geriatrics Society 2019 Updated AGS Beers Criteria ${ }^{\circledR}$ for potentially inappropriate medication use in older adults. J Am Geriatr Soc. 2019;67(4):674-94. https://doi.org/10.1111/ jgs. 15767.

21. Szabo SM, Gooch K, Schermer C, Walker D, Lozano-Ortega $\mathrm{G}$, Rogula B, et al. Association between cumulative anticholinergic burden and falls and fractures in patients with overactive bladder: US-based retrospective cohort study. BMJ Open. 2019;9(5):e026391. https://doi.org/10.1136/bmjopen-2018-02639 1.

22. Yoshida M, Kato D, Nishimura T, Van Schyndle J, Uno S, Kimura T. Anticholinergic burden in the Japanese elderly population: Use of antimuscarinic medications for overactive bladder patients. Int J Urol. 2018;25(10):855-62. https://doi.org/10.1111/iju.13758.

23. Centers for medicare and medicaid services. Long Term Care Minimum Data Set (MDS) 3.0-Data Documentation 2020. https ://www.resdac.org/cms-data/files/mds-3.0/data-documentation. Accessed 25 Aug 2020.

24. Centers for Medicare and Medicaid Services. Medicare standard analytical files: identifiable data files. http://www.cms.hhs.gov/ IdentifiableDataFiles/02_StandardAnalyticalFiles.asp. Accessed 25 Aug 2020.

25. Services CfMaM. Research Data Assistance Center (ResDAC): available CMS data. 2020. https://www.resdac.org/file-availabili ty. Accessed 25 Aug 2020.

26. Wei YJ, Simoni-Wastila L, Zuckerman IH, Brandt N, Lucas JA. Algorithm for identifying nursing home days using medicare claims and minimum data set assessment data. Med Care. 2016;54(11):e73-7. https://doi.org/10.1097/mlr.0000000000 000109 .

27. Lozano-Ortega G, Johnston KM, Cheung A, Wagg A, Campbell NL, Dmochowski RR, et al. A review of published anticholinergic scales and measures and their applicability in database analyses. Arch Gerontol Geriatr. 2020;87:103885. https://doi.org/10.1016/j. archger.2019.05.010.

28. Boustani M, Campbell N, Munger S, Maidment I, Fox C. Impact of anticholinergics on the aging brain: a review and practical application. Aging Health. 2008;4(3):311-20. https://doi. org/10.2217/1745509X.4.3.311.

29. WHO Collaborating Centre for Drug Statistics Methodology. Guidelines for ATC classification and DDD assignment 2020. Oslo: WHO Collaborating Centre for Drug Statistics Methodology; 2019.

30. Andersen R, Newman JF. Societal and individual determinants of medical care utilization in the United States. Milbank Mem Fund Q Health Soc. 1973;51(1):95-124. https://doi.org/10.2307/33496 13 .

31. Babitsch B, Gohl D, von Lengerke T. Re-revisiting Andersen's Behavioral Model of Health Services Use: a systematic review of studies from 1998-2011. Psychosoc Med. 2012;9:Doc11. doi:https ://doi.org/10.3205/psm000089.

32. Steinbeisser K, Grill E, Holle R, Peters A, Seidl H. Determinants for utilization and transitions of long-term care in adults 65+ in Germany: results from the longitudinal KORA-Age study. BMC Geriatr. 2018;18(1):172. https://doi.org/10.1186/s1287 7-018-0860-x

33. Geerlings SW, Margriet Pot A, Twisk JWR, Deeg DJH. Predicting transitions in the use of informal and professional care by older adults. Ageing Soc. 2005;25(1):111-30. https://doi.org/10.1017/ S0144686X04002740.

34. Wong A, Elderkamp-de Groot R, Polder J, van Exel J. Predictors of long-term care utilization by dutch hospital patients aged 65+. BMC Health Serv Res. 2010;10(1):110. https://doi. org/10.1186/1472-6963-10-110.

35. Wu CY, Hu HY, Huang N, Fang YT, Chou YJ, Li CP. Determinants of long-term care services among the elderly: a populationbased study in Taiwan. PLoS ONE. 2014;9(2):e89213. https://doi. org/10.1371/journal.pone.0089213.

36. Elixhauser A, Steiner C, Harris DR, Coffey RM. Comorbidity measures for use with administrative data. Med Care. 1998;36(1):8-27. https://doi.org/10.1097/00005650-19980100000004.

37. Ivchenko A, Bödeker RH, Neumeister C, Wiedemann A. Anticholinergic burden and comorbidities in patients attending treatment with trospium chloride for overactive bladder in a real-life setting: results of a prospective non-interventional study. BMC Urol. 2018;18(1):80. https://doi.org/10.1186/s12894-018-0394-8.

38. Kojima G, Bell C, Tamura B, Inaba M, Lubimir K, Blanchette PL, et al. Reducing cost by reducing polypharmacy: the polypharmacy outcomes project. J Am Med Dir Assoc. 2012;13(9):818.e11-5. https://doi.org/10.1016/j.jamda.2012.07.019.

39. Palmer JB, Albrecht JS, Park Y, Dutcher S, Rattinger GB, SimoniWastila L, et al. Use of drugs with anticholinergic properties among nursing home residents with dementia: a national analysis of Medicare beneficiaries from 2007 to 2008. Drugs Aging. 2015;32(1):79-86. https://doi.org/10.1007/s40266-014-0227-8.

40. Aalto UL, Roitto HM, Finne-Soveri H, Kautiainen H, Pitkälä KH. Temporal trends in the use of anticholinergic drugs among older people living in long-term care facilities in Helsinki. Drugs Aging. 2020;37(1):27-34. https://doi.org/10.1007/s40266-019-00720-6.

41. Fox C, Smith T, Maidment I, Chan WY, Bua N, Myint PK, et al. Effect of medications with anti-cholinergic properties on cognitive function, delirium, physical function and mortality: a systematic review. Age Ageing. 2014;43(5):604-15. https://doi.org/10.1093/ ageing/afu096.

42. Gerretsen P, Pollock BG. Drugs with anticholinergic properties: a current perspective on use and safety. Expert Opin Drug Saf. 2011;10(5):751-65. https://doi.org/10.1517/14740 338.2011.579899.

43. Wagg A, Khullar V, Marschall-Kehrel D, Michel MC, Oelke M, Darekar A, et al. Flexible-dose fesoterodine in elderly adults with overactive bladder: results of the randomized, double-blind, placebo-controlled study of fesoterodine in an aging population trial. J Am Geriatr Soc. 2013;61(2):185-93. https://doi.org/10.1111/ jgs. 12088 .

44. Kelleher CJ, Cardozo L, Chapple CR, Haab F, Ridder AM. Improved quality of life in patients with overactive bladder symptoms treated with solifenacin. BJU Int. 2005;95(1):81-5. https:// doi.org/10.1111/j.1464-410X.2004.05255.x.

45. Toglia MR, Serels SR, Laramée C, Karram MM, Nandy IM, Andoh M, et al. Solifenacin for overactive bladder: patientreported outcomes from a large placebo-controlled trial. Postgrad Med. 2009;121(5):151-8. https://doi.org/10.3810/ pgm.2009.09.2062.

46. O'Malley KJ, Cook KF, Price MD, Wildes KR, Hurdle JF, Ashton CM. Measuring diagnoses: ICD code accuracy. Health Serv Res. 2005;40(5 Pt 2):1620-39. https://doi.org/10.111 $1 / \mathrm{j}$.1475-6773.2005.00444.x. 